\title{
Effects of Acute Ovariectomy on the Lordosis Response of Female Rats
}

\author{
JUDITH K. MOREINES AND J. BRADLEY POWERS ${ }^{2}$ \\ Department of Psychology and Neuroscience Laboratory, University of Michigan, \\ Ann Arbor, MI 48109
}

(Received 27 November 1976)

\begin{abstract}
MOREINES, J. AND J. B. POWERS. Effects of acute ovariectomy on the lordosis response of female rats. PHYSIOL. BEHAV. 19(2) 277-283,1977. - The sexual receptivity of in tact females with 4- or 5-day estrous cycles was compared to that of other females which had been ovariectomized at particular times during their cycles. The quality and frequency of lordosis responding were more degraded the earlier during the cycle ovariectomy was performed. This effect was more pronounced in 4-day than in 5-day cyclic females. Because exogenous progesterone was administered to all ovariectomized females, these behavioral deficits were attributed to removal of ovarian estradiol. Ovariectomy $6 \mathrm{hr}$ before the critical period for luteinizing hormone release significantly shortened the duration of behavioral estrus, even though it had no effect when lordosis was tested at the time intact estrous females are maximally receptive. These findings are consistent with the hypothesis that the continual availability of estradiol throughout the $18-24 \mathrm{hr}$ interval prior to the onset of behavioral estrus is essential for optimal conditioning of sexual receptivity to occur under physiological conditions. The relevance of triggering and maintenance functions of estradiol to these results is discussed.
\end{abstract}

Lordosis Acute ovariectomy Sexual receptivity Estradiol

Estrous cycle Behavioral estrus.

MANY FEMALE rodents become sexually receptive following the synergistic action of estrogen and progesterone. This has been demonstrated both in females undergoing normal estrous cycles and in ovariectomized animals after exogenous hormone administration $[17,26]$. The mechanisms by which ovarian steroids interact to initiate and sustain sexual receptivity are poorly understood. Some insight into the nature of these mechanisms has been gained by testing the effects on lordosis of various pharmacological agents which can disrupt potentially relevant neurochemical processes. These studies have suggested that estradiol interactions with brain cell nuclei, resulting in altered protein synthetic activities, are necessary for the eventual expression of lordosis $[35,37,41,45]$. Because approximately $18-24 \mathrm{hr}$ must elapse after estradiol administration before progesterone can facilitate sexual receptivity [13, 18,38 ], it is reasonable to suppose that this latent period represents the time during which relevant metabolic processes occur. There is some disagreement concerning whether or not estradiol must continue to be available once these neurochemical processes have been initiated. For example, lordosis can be elicited approximately $24 \mathrm{hr}$ after an injection of estradiol when none of the injected steroid remains in the brain [29]. This evidence favors the view that estradiol functions primarily to trigger, or turn on, relevant brain mechanisms. On the other hand, some investigators have suggested that estradiol subserves not only a triggering but also a maintenance function $[5,13$, 15,161 . Although the precise nature of this hypothetical maintenance function has not been clearly specified, it draws attention to the possibility that estradiol may have to be available systemically or retained intracellularly [25] over relatively long durations in order for optimal behavioral effects to be achieved.

Experiments concerned with possible functions of estradiol in mediating sexual receptivity have been based for the most part on the behavior of ovariectomized females receiving exogenous hormone treatment. It is difficult to assess the relevance that such experimental approaches might have to understanding the action of estradiol during the estrous cycle. Two factors are particularly germane. One is that after ovariectomy, behavioral responsiveness to ovarian hormones declines $[4,12,19]$. This most likely reflects an altered sensitivity to exogenous steroid treatment, but the relevant causal mechanisms have not been established. However, this lowered sensitivity is probably not due to reduced numbers of brain estradiol receptors following ovariectomy [11]. A second point to be considered is that the pattern of hormone availability following exogenous administration is different from the pattern that occurs during the estrous cycle. In the latter case, peripheral levels of estradiol rise gradually, reaching a peak just

\footnotetext{
${ }^{1}$ Research supported by NIH Grant No. 1 RO1 HD08281-01.

${ }^{2}$ Send reprint requests to Dr. J. Bradley Powers, Neuroscience Laboratory, 1103 E. Huron, University of Michigan, Ann Arbor, MI 48109.
} 
a few hours before the onset of receptivity $[9,23,24,42$, 43]. Following exogenous treatment, peak estradiol levels are reached within minutes after injection which then fall at a rate depending on the form of estrogen administered [44].

For these reasons, it seems quite probable that estradiol, when administered exogenously to ovariectomized females, affects brain mechanisms controlling lordosis in ways that may be different from those which occur under physiological conditions. In the experiments reported here we assessed the relevance of the estradiol secreted during varying portions of the estrous cycle to the regulation of behavioral estrus as it normally occurs in intact females.

\section{GENERAL PROCEDURES}

Sprague-Dawley female rats (Holtzman; Madison, WI) were housed individually under a $14 \mathrm{hr}$ light: $10 \mathrm{hr}$ dark illumination schedule (lights off between $11 \mathrm{a} . \mathrm{m}$. and 9 p.m.). Estrous cycles were monitored by palpating the flanks and perineum once each day during the $10 \mathrm{hr}$ dark period and noting the appearance of a lordosis response. This technique constitutes a reliable check of estrous cycle length [47]. A minimum of 3 consecutive four (4D) or five day (5D) cycles was observed before any female was accepted for use.

All experimental treatments and behavioral tests were conducted with respect to an arbitrary reference time during the estrous cycle $(0 \mathrm{hr}=6 \mathrm{a} . \mathrm{m}$.$) which coincided$ with the beginning of the critical period for luteinizing hormone $(\mathrm{LH})$ release [30]. This reference point and other relevant experimental times are indicated in Fig. 1 which schematically presents the temporal patterns of estradiol and progesterone secretion during the $5 \mathrm{D}$ estrous cycle. It is intended to emphasize simply that peripheral blood levels of estradiol rise gradually over a $1-2$ day period prior to $0 \mathrm{hr}$, whereas enhanced secretion of progesterone occurs subsequent to $0 \mathrm{hr}$.

Acute ovariectomies (OVX) were performed in different groups at various times as shown in Fig. 2. Females were OVX under methoxyflurane anesthesia (Penthrane, Abbott Laboratories) by making a single ventral midline incision, cutting the abdominal musculature, ligating the uterine horns, and removing the ovaries. These animals, anesthetized for approximately $10 \mathrm{~min}$, were fully abulatory $15-20 \mathrm{~min}$ after surgery.

The effects of acute OVX were assessed by scoring the number and quality of lordosis responses elicited by sexually active Long-Evans male rats previously adapted to semicircular mating chambers $(76 \mathrm{~cm}$ dia. and $40 \mathrm{~cm}$ in height and width). The intensity of each lordosis response was assigned a value of $0-3$, representing gradations from no concave arching of the back to maximal lordosis. Responses to 10 adequate mounts were obtained, and the mean lordosis rating was used as the receptivity score (RS). Lordosis quotients (LQ's) were also obtained by counting all non-zero responses and expressing them as a percentage of the total number possible [10] in each test. Because analysis of LQ's provided information essentially identical to that derived from analysis of receptivity scores, only the latter are presented. When progesterone $(\mathbf{P})$ was administered to experimental females, $0.5 \mathrm{mg} /$ animal in $0.1 \mathrm{ml}$ sesame oil was injected subcutaneously.

All statistical evaluations were performed using the

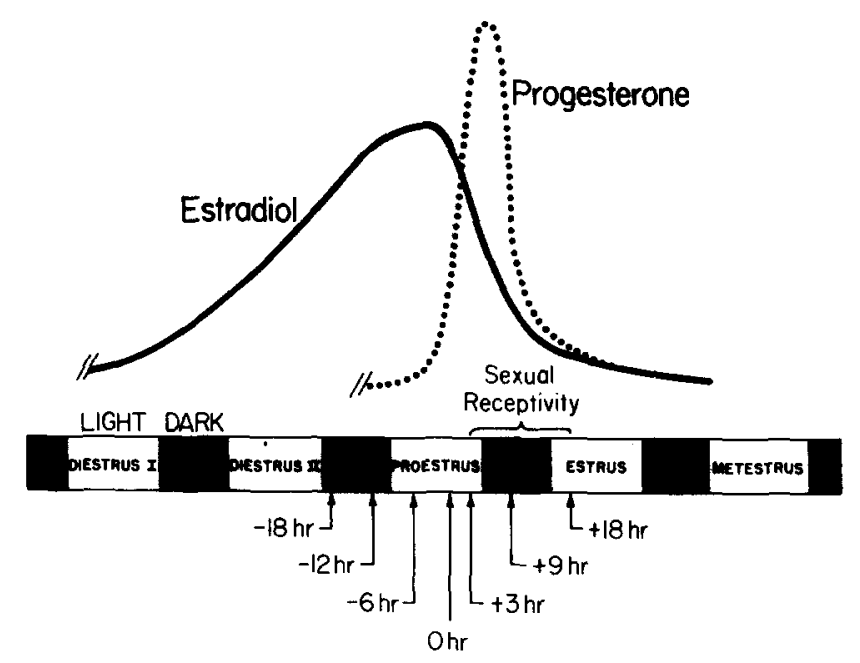

FIG. 1. Schematic depiction of estradiol and progesterone secretory patterns during 5-day estrous cycles with indicated hours representing times of either acute ovariectomy, progesterone treatment or behavior testing (see text). The arbitrary origin $(0 \mathrm{hr})$ corresponds with the onset of the critical period for luteinizing hormone release and precedes the time during which sexual receptivity is maximally displayed in intact females. Cycle days begin and end at the mid-points of successive dark periods. The indicated hours correspond to the following clock times in the 14L: 10D cycle (lights on between 0500 and 1900 ) commonly used in neuroendocrine research: $-18 \mathrm{hr}$ is 2000 Diestrus II; $-12 \mathrm{hr}$ is 0200 Proestrus (Pro); $-6 \mathrm{hr}$ is 0800 Pro; $0 \mathrm{hr}$ is $1400 \mathrm{Pro} ;+3 \mathrm{hr}$ is 1700 Pro; $+9 \mathrm{hr}$ is 2300 Pro; $+18 \mathrm{hr}$ is 0800 Estrus.

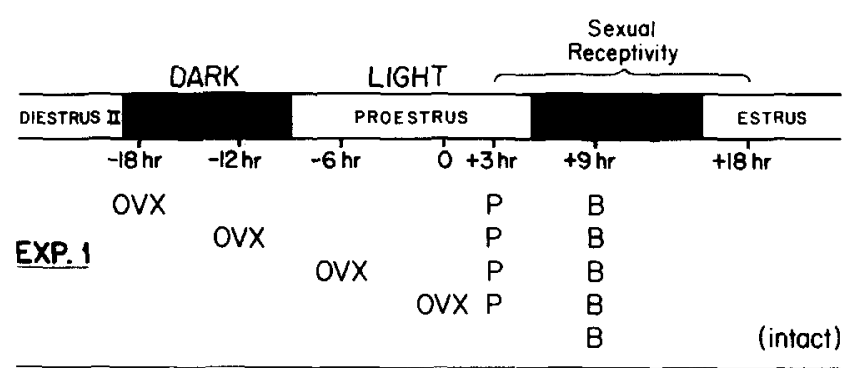

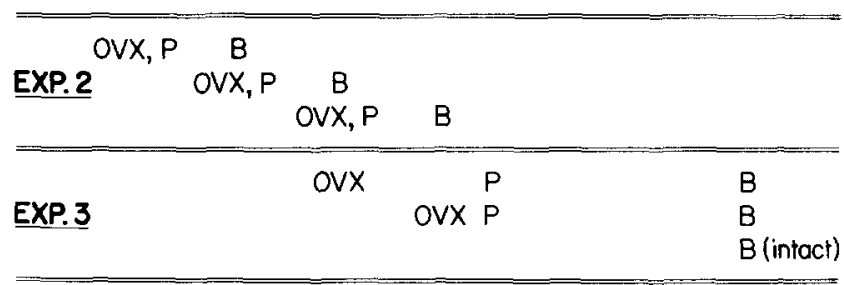

FIG. 2. Treatment paradigms used in Experiments 1-3. Cycle days, illumination conditions, and the time of maximal sexual receptivity in intact females are shown with reference to $0 \mathrm{hr}$. OVX ovariectomy; $\mathrm{P}-0.5 \mathrm{mg}$ progesterone/animal; $\mathrm{B}$ - mating behavior tests.

Kruskal-Wallis, Mann-Whitney, or nonparametric pairedcontrast tests where appropriate.

\section{EXPERIMENT 1}

The general strategy of this experiment was to assess the extent to which the sexual responsiveness of female rats 
would be affected by removing endogenous estradiol at varying times prior to the expected period of maximal behavioral estrus. If estrogen conditioning in the intact female depends primarily upon an early triggering action of estradiol, it should be expected that ovariectomy within the $12-18 \mathrm{hr}$ prior to $\mathrm{LH}$ release would not significantly degrade the quality of lordosis subsequently displayed because elevated estradiol levels would already have been present for approximately $24 \mathrm{hr}$. However, if long-term exposure of the brain to estradiol is an essential feature of the estrogen conditioning process, behavioral deficits would be expected following acute ovariectomy during this period.

Experiments by Nequin and Schwartz [33] demonstrated that OVX earlier than $-6 \mathrm{hr}$ in $4 \mathrm{D}$ or $-8 \mathrm{hr}$ in $5 \mathrm{D}$ (Fig. 1) estrous cycles interfered with the display of lordosis. However, these results were based on the appearance of the first lordosis response rather than on a qualitative assessment of sexual responsiveness. In addition, exogenous progesterone was not provided which raises serious problems because the normal expression of lordosis during the estrous cycle requires the action of this steroid $[3,34]$. Thus lowered sexual responsiveness following acute OVX during the estrous cycle can be jointly influenced by deficiencies in both estradiol and progesterone secretion. In the present experiments, progesterone was administered to all acutely OVX females so that altered behavioral responsiveness could not be attributed to a lack of this hormone.

\section{Method}

Thirty females exhibiting 5D estrous cycles were assigned in equal numbers to 1 of 5 different experimental conditions depicted in Fig. 2. The ovaries of these animals either remained intact or were removed at one of 4 time points during the estrous cycle. These were $18,12,6$, or $0 \mathrm{hr}$ prior to the beginning of the critical period for $\mathrm{LH}$ release. Twenty-four females exhibiting 4D estrous cycles were given comparable treatments except that a group receiving $-18 \mathrm{hr}$ OVX was not included. All OVX females were administered $\mathrm{P}$ at $+3 \mathrm{hr}$. The dose used $(0.5 \mathrm{mg} /$ animal) has been previously demonstrated to facilitate receptivity in $0 \mathrm{hr}$ OVX females [34], and the injection time was chosen to correspond with the LH-induced progesterone surge under physiological conditions [14]. All OVX females were given a single mating behavior test at +9 hr; for comparison, intact females were tested at the same time during the evening of their behavioral estrus periods.

\section{Results}

Receptivity scores of intact and acutely OVX females are shown in Fig. 3. Both intact and $0 \mathrm{hr}$ OVX females display uniformly high levels of sexual responsiveness. This establishes that the stress of surgery does not interfere with the expression of lordosis $9 \mathrm{hr}$ later, and that by $0 \mathrm{hr}$, ovarian secretions are sufficient to induce behavioral estrus when supplemented by progesterone. Time of OVX has a significant overall effect on $\mathrm{RS}$ in both $4 \mathrm{D}(\mathrm{H} 3)=8.0$, $p<0.05$, and $5 \mathrm{D}$ cycles, $\mathrm{H}(4)=12.3, p<0.02$. Following $-12 \mathrm{hr}$ OVX in $4 \mathrm{D}$ or $-18 \mathrm{hr}$ OVX in $5 \mathrm{D}$ cycles, a minimal quality of lordosis is displayed. Paired contrast tests indicate that among 4D females, those $\mathrm{OVX}$ at $-12 \mathrm{hr}$ are significantly less receptive than intacts $(p<0.05)$. RS's of $5 \mathrm{D}$ females OVX at $-18 \mathrm{hr}$ are significantly lower than the

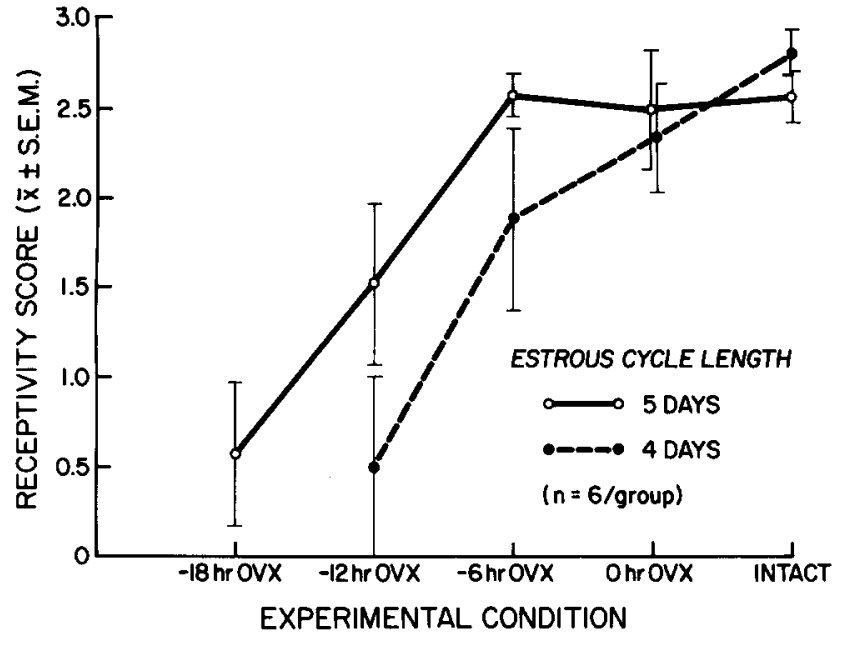

FIG. 3. Receptive behavior following acute OVX in females with previously established 4-day or 5-day estrous cycles. Separate groups were OVX at the varying times indicated but all females received $P$ at $+3 \mathrm{hr}$ and were tested for sexual receptivity at $+9 \mathrm{hr}$. Intact females were also tested at $+9 \mathrm{hr}$ but were otherwise untreated (see

Fig. 2).

RS's of intacts or of females OVX at either $-6 \mathrm{hr}$ or $0 \mathrm{hr}$ $(p<0.05)$. The remaining comparisons within 4D or 5D cycles are not significant.

The effects of acute OVX depend to some extent on estrous cycle duration. At each time of OVX prior to $0 \mathrm{hr}$, females with $4 \mathrm{D}$ cycles show greater behavioral deficits than do those with 5D cycles; however, because of the large variability in RS's, these differences only approach significance. Thus in both 4D and 5D cycles, ovarian hormones secreted early during the estrous cycle are insufficient to condition receptive behavior mechanisms so that lordosis can be displayed at a time when intact females are maximally responsive.

\section{EXPERIMENT}

Experiment 1 demonstrates that the terminal 12 to $18 \mathrm{hr}$ period of ovarian secretory activity preceding the $\mathrm{LH}$ surge is important for the subsequent expression of lordosis. It is not clear from these findings, however, to what extent the time imposed between acute ovariectomy and progesterone administration might contribute to the attenuated sexual responsiveness observed. For example, by $-18 \mathrm{hr}$ in the $5 \mathrm{D}$ cycle, adequate estrogen conditioning may be achieved but this state rapidly dissipates without continued estradiol availability. If this is the case, it should be possible to elicit higher quality estrous behavior if the latency between $P$ injections and acute $O V X$ is reduced. Experiments demonstrating that the onset of receptive behavior during the estrous cycle can be advanced by appropriately timed progesterone injections $[2,47]$ provide some support for this idea. These results suggest that the estrogen conditioning process has been completed sometime prior to the time when lordosis is normally expressed during the cycle. This possibility was further tested in the following experiment. 


\section{Method}

Eighteen females exhibiting 5D cycles were assigned to one of 3 conditions. The timing of acute OVX, $P$ treatment and behavior testing for these 3 groups is shown in Fig. 2 . In general, OVX was done at times comparable to those of Experiment 1 with the omission of $0 \mathrm{hr}$, but in each case $P$ was injected immediately following OVX just after the females had recovered from the anesthetic; receptivity scores were obtained $6 \mathrm{hr}$ later. Thus, for this experiment the timing of OVX, P treatment, and subsequent behavior testing varied among groups, whereas in Experiment 1 only the time of OVX was varied.

\section{Results}

Figure 4 presents the receptivity scores of females in this experiment and for comparison it depicts the behavioral effects of OVX at comparable times as tested in Experiment 1 . It is apparent that the RS's elicited when progesterone is given immediately after OVX are in most cases lower than the RS's observed following identical times of OVX when progesterone is given at $+3 \mathrm{hr}$ (Experiment 1). The earlier times of $P$ injection and behavior testing result in significantly lower receptivity scores only after $-6 \mathrm{hr}$ OVX $(p=0.03)$. The females in this group as well as those OVX earlier $(-12 \mathrm{hr}$ and $-18 \mathrm{hr})$ have RS's significantly lower than intact $5 \mathrm{D}$ females tested at $+9 \mathrm{hr}$ (Fig. 3; $p=0.03$ ). These data support the findings of Experiment 1 that in $5 \mathrm{D}$ cycles the estrogen conditioning process for lordosis has not been completed by $-12 \mathrm{hr}$. They also suggest that regardless of when the ovaries are removed, optimal facilitation of lordosis is achieved by administering progesterone at a time when endogenous levels are reaching their peak values during intact cycles, i.e., at approximately $+3 \mathrm{hr}$. The reduced effectiveness of progesterone given earlier during the cycle could be related to differences in the extent of estrogen conditioning, in the sensitivity of the brain to progesterone, or in the responsiveness of other mechanisms more directly related to the expression of lordosis.

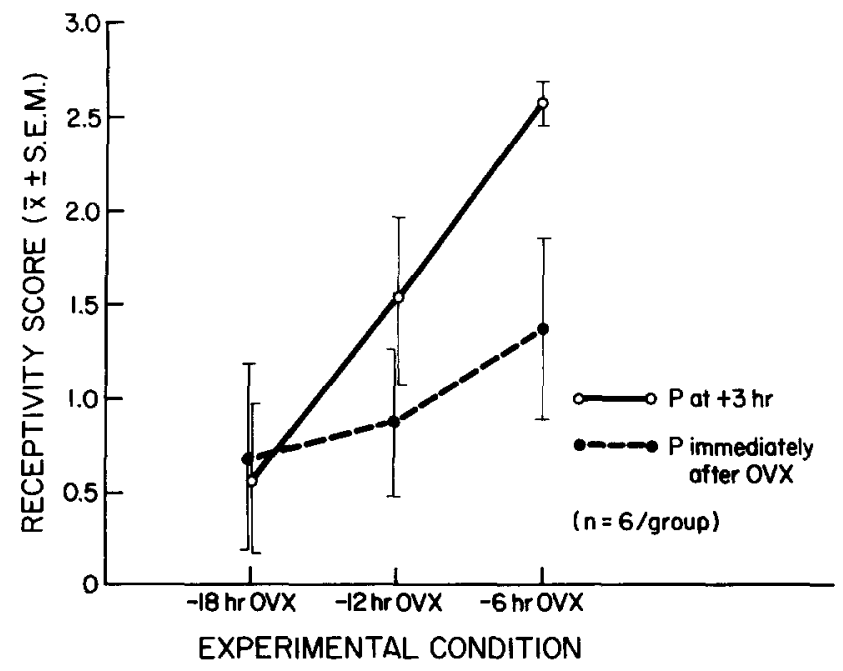

FIG. 4. Receptive behavior following acute OVX and $P$ treatment in females with previously established 5-day estrous cycles. Separate groups were OVX at the varying times indicated and administered $P$ immediately after OVX (see Fig. 2). For comparison, data from Experiment 1 are shown in which $P$ was given at $+3 \mathrm{hr}$.

\section{EX PERIMENT 3}

The results of Experiment 1 and 2 are consistent with the hypothesis that continual availability of ovarian estradiol throughout the estrous cycle is a necessary prerequisite for optimal sexual responsiveness to occur under physiological conditions. One finding, however, provides an exception. In females with $5 D$ cycles the ovaries can be removed at $-6 \mathrm{hr}$ without significant deterioration in the lordosis response when tested at $+9 \mathrm{hr}$ (Fig. 3). However, even in this case it remains possible that sexual responsiveness is altered in ways not detected by our experimental paradigm. In previous work, we have asserted that the duration of behavioral estrus is controlled primarily by an effect of estrogen rather than by inhibitory actions of progesterone $[34,36]$ Thus it seems reasonable that limiting the period of estradiol availability by acute OVX might be most sensitively reflected in a shortened period of estrus. In Experiment 3 we examined this possibility by testing lordosis after acute OVX but at later times during the cycle than we had in Experiment 1 .

\section{Method}

We initially established that intact 5D females in behavioral estrus display lordosis at $+18 \mathrm{hr}$ but not at $+24 \mathrm{hr}$. To assess the effects of acute OVX on estrous duration, we chose to measure receptivity on a single test at $+18 \mathrm{hr}$. Significantly lowered receptivity scores at this time reflect an abbreviated duration of behavioral estrus. This single test was considered preferable to multiple tests throughout the estrous period because of the variable effects which copulatory stimulation can have on subsequent sexual responsiveness $[18,20,40]$. Females either remained intact, or were $\mathrm{OVX}$ at $0 \mathrm{hr}(4 \mathrm{D}, \mathrm{n}=10 /$ group; $5 \mathrm{D}, \mathrm{n}=7 /$ group $)$ or at $-6 \mathrm{hr}(5 \mathrm{D}, \mathrm{n}=7)$. Receptivity scores were obtained at $+18 \mathrm{hr}$ with OVX animals receiving $0.5 \mathrm{mg} \mathrm{P}$ at $+3 \mathrm{hr}$.

\section{Results}

The sexual receptivity of both 4D and 5D intact estrous females is high at $+18 \mathrm{hr}$ and not significantly different from the behavioral responsiveness of intact females tested at $+9 \mathrm{hr}$ (Experiment 1). Ovariectomy at $0 \mathrm{hr}$ in 5D females has no detectable effect on estrous duration (Fig. 5). Receptivity scores at $+18 \mathrm{hr}$ are not significantly different from those of intact females tested at this time. Likewise, the difference between $+9 \mathrm{hr}$ (Experiment 1$)$ and $+18 \mathrm{hr}$ RS's of $0 \mathrm{hr}$ OVX females is not significant. Similar results were obtained with $4 \mathrm{D}$ females $\mathrm{OVX}$ at $0 \mathrm{hr}$; their mean RS's at +9 and +18 hrs were 2.3 and 1.9 , respectively. In contrast, OVX at $-6 \mathrm{hr}$ markedly abbreviates estrous duration. This treatment totally abolishes behavioral responsiveness at $+18 \mathrm{hr}$, whereas it has little effect on +9 hr receptivity scores $(p<0.001)$. These results establish that the temporal limits within which lordosis can be expressed are significantly influenced by ovarian secretions occurring up to the critical period for $\mathrm{LH}$ release $(0 \mathrm{hr})$. They also indicate that subsequent to $0 \mathrm{hr}$ ovarian secretions with the exception of progesterone [34] are not required to assure a normal duration of behavioral estrus in both $4 \mathrm{D}$ and $5 \mathrm{D}$ females.

\section{Discussion}

Acute ovariectomy during 4- and 5-day estrous cycles 


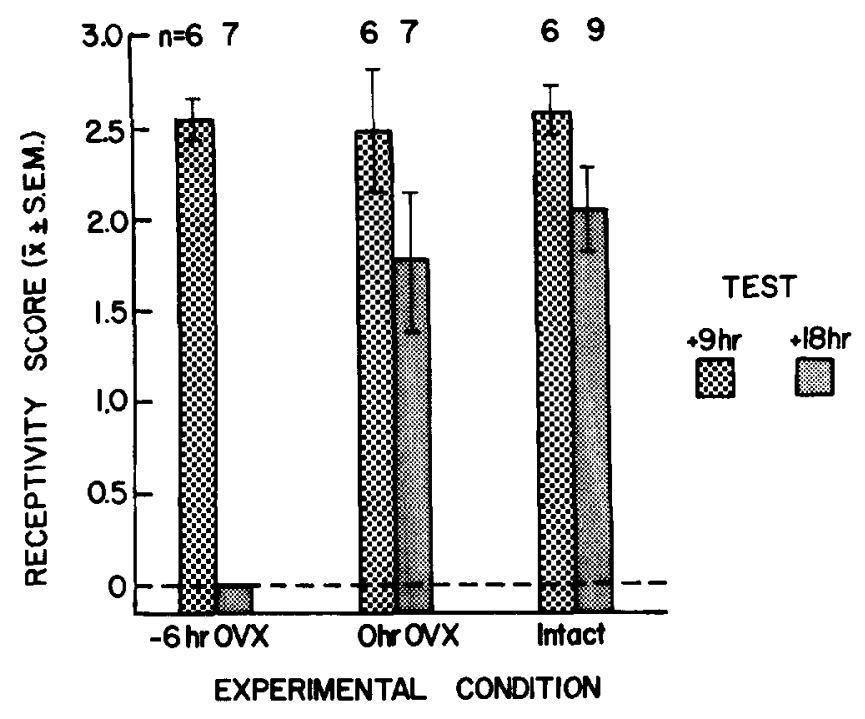

FIG. 5. Receptive behavior of females with previously established 5 -day estrous cycles and either left intact or acutely OVX at the times indicated. All OVX females received $P$ at $+3 \mathrm{hr}$; separate groups were tested at either $+9 \mathrm{hr}$ or $+18 \mathrm{hr}$ (see Fig. 2).

can markedly attenuate the quality of lordosis elicited by sexually vigorous males during the evening of proestrus (Fig. 3, 4, 5). Because exogenous progesterone was always administered following OVX, the observed behavioral deficits are most likely due to the removal of ovarian estradiol although no independent proof of this has been provided by the experiments described here. Tapper, et al. [44], however, have demonstrated that exogenous estradiol benzoate followed by progesterone is able to reinstate sexual receptivity in female rats ovariectomized very early during their estrous cycles and we have obtained similar results using silastic implants of estradiol (unpublished). Contrary evidence has recently been published by Nequin, et al. [31]. They reported that $-6 \mathrm{hr}$ OVX had no significant effect on estradiol levels over the following $6 \mathrm{hr}$ period. This finding most likely reflects the presence of an adrenal product which cross-reacted with the estradiol antibodies used for radioimmunoassay [46] but which is probably not a biologically active estrogen [39].

A systematic relation exists between the time of ovariectomy during the estrous cycle and the quality of sexual behavior subsequently displayed (Fig. 3 and 4). Although the general nature of this function is not unexpected, the extent to which a $6 \mathrm{hr}$ period of ovarian secretory activity shortly before $0 \mathrm{hr}$ so obviously affects the duration of behavioral estrus is striking (Fig. 5). It can be concluded from this finding that the intensity and duration of sexual responsiveness normally displayed by intact females under physiological conditions requires the full complement of estradiol secreted prior to the progesterone surge.

Our experimental design did not include behavioral tests of females sham ovariectomized at varying times during the estrous cycle. The most obvious question this raises is to what extent the behavioral effects observed following removal of the ovaries might be attributable to nonspecific factors unrelated to the termination of estradiol secretion. Because it would be expected that nonspecific effects due to our OVX procedures should be more debilitating the sooner behavior was tested following the stress of surgery we considered $0 \mathrm{hr} O V X$ to be an adequate control procedure. In no case did this treatment significantly attenuate receptivity scores when compared to unoperated females. Thus it is unlikely that the behavioral deficits resulting from OVX at earlier times during the estrous cycle can be attributed to nonspecific factors.

The findings reported here on the mating behavior of acutely ovariectomized females support and extend the work of other investigators using rats [3, 33, 34, 44], guinea pigs [21] and hamsters $[6,10]$. The most directly comparable results are those of Nequin and Schwartz [33] who showed that by $-8 \mathrm{hr}$ the estrogen conditioning process was sufficient to support lordosis in female rats with $5 \mathrm{D}$ cycles, but inadequate in females with 4D cycles. This is consistent with the differences we found between OVX at $-6 \mathrm{hr}$ during 4D and 5D cycles (Fig. 3). In the latter case sexual responsiveness was not different from intact levels whereas in 4D females some degradation in receptivity was found. Additionally, $-12 \mathrm{hr}$ OVX significantly lowered receptivity scores only in $4 \mathrm{D}$ females.

These differential effects of acute ovariectomy in females with $4 D$ or 5D cycles are consistent with the fact that under physiological conditions the onset of receptive behavior is earlier on the average in $5 \mathrm{D}$ than $4 \mathrm{D}$ cycles [33]. This is presumably related to an action of adrenal progesterone. At times during both $4 \mathrm{D}$ and $5 \mathrm{D}$ cycles when elevated levels of this hormone may synchronize the timing of $\mathrm{LH}$ release $[14,27,28]$, the estrogen conditioning process is sufficiently complete for progesterone to facilitate early receptivity only in 5D females. Differences in estrogen-conditioning between $4 \mathrm{D}$ and $5 \mathrm{D}$ cycles are also in accord with measures of circulating estradiol which suggest that peripheral levels are elevated above baseline for approximately $24 \mathrm{hr}$ longer in 5D cycles $[7,30,32]$ although there are contradictory findings [23,24]. Thus after OVX at either $-6 \mathrm{hr}$ or $-12 \mathrm{hr}$ it is not surprising that 4D females show greater behavioral deficits for they have been exposed to the conditioning actions of estradiol over a shorter interval.

The results presented here are to some extent in conflict with findings from other experiments; these studies attempted to advance the onset of behavioral estrus in intact females by injections of progesterone. In both 4D [2] and $5 \mathrm{D}$ cycles [47], sexual receptivity could be induced at approximately $-15 \mathrm{hr}$ to $-10 \mathrm{hr}, 3$ to 5 hours after progesterone treatment. Based on these findings it was concluded that the estrogen conditioning process for lordosis was completed prior to the time that this behavior normally began. In our experiments, the earliest we tested females was at $-12 \mathrm{hr}, 6 \mathrm{hr}$ after OVX at $-18 \mathrm{hr}$ in Experiment 2 (5-day cycles). Under these conditions females were unreceptive (Fig. 4). Even when the ovaries remained in situ for an additional $6 \mathrm{hr}$ (OVX at $-12 \mathrm{hr}$ ), subsequent receptivity was not intense and was characterized by extreme variability among females. This was true regardless of whether exogenous progesterone was given immediately after the OVX (Experiment 2), or later when the endogenous surge would normally occur $(+3 \mathrm{hr})$ (Experiment 1). In 4-day cycles, OVX at $-12 \mathrm{hr}$ resulted in very low receptivity scores (Fig. 3 ). Thus, our evidence does not suggest that estrogen conditioning in either $4 \mathrm{D}$ or $5 \mathrm{D}$ cycles is complete by $-12 \mathrm{hr}$.

There are a number of important factors to consider in 
attempting to reconcile our findings with those derived from endogenous progesterone administration to intact females. First, the procedures used to assess the presence of receptive behavior were different among the three laboratories; in our case variations in the quality of behavior in response to a male were taken into consideration. Secondly, the quantity of progesterone used to facilitate behavioral estrus was 4 times higher in the experiments using intact females than it was in our studies. Possibly had we used larger doses, the resultant behavior would have been of higher quality. Thirdly, it cannot be overlooked that exogenous progesterone administered to intact females modifies gonadal and pituitary hormone secretion $[8,24]$. The extent to which these factors, particularly a change in the availability of gonadal steroids, might influence the subsequent display of sexual receptivity, has not been established.

It is interesting to note that Joslyn, et al. [21] observed a similar difference between the facilitating effects of progesterone administered to intact or acutely ovariectomized guinea pigs prior to the onset of spontaneous behavioral estrus. The percentage of females showing lordosis following acute OVX and $\mathbf{P}$ treatment on Day 15 (spontaneous estrus occurs on Day 16) was significantly lower than the percentage of intact females which became receptive on Day 15 following comparable $P$ injections. Although a number of factors were tested which might have accounted for this differential effect, none was found.

The results of the present experiment clearly suggest that all of the estradiol secreted prior to the LH surge is essential to the physiological regulation of behavioral estrus. It is not apparent, however, to what extent this represents a maintenance function of estradiol. The distinctions which have been made between triggering and maintenance functions imply that they involve differing mechanisms of action. It has been suggested that a maintenance function might be subserved by a mechanism acting to prolong the time over which estradiol-receptor complexes are retained in relevant brain cell nuclei [25]. There is some evidence that the biological effectiveness of estradiol in uterine tissue is modulated by the time hormone-receptor complexes are held in the nucleus [1]; whether this is also true in the central nervous system is not known.

Based on our findings it seems clear that the estradiol available and taken up by brain cells prior to $-18 \mathrm{hr}$ is not sufficient to adequately condition lordosis mechanisms (Fig. 3). What becomes available subsequent to $-18 \mathrm{hr}$ obviously provides an essential input to this behavioral system. This was particularly evident in Experiment 3 in which the duration of estrus was shortened by OVX at $-6 \mathrm{hr}$. Because $-6 \mathrm{hr}$ OVX eliminated receptivity at $+18 \mathrm{hr}$ (Fig. 5), it is apparent that the ovarian hormones secreted between $-6 \mathrm{hr}$ and $0 \mathrm{hr}$ are necessary for lordosis to be expressed $18-24 \mathrm{hr}$ later.

We do not wish to imply that the only estrogenic requirement for an adequate lordosis response is that estradiol be available $18-24 \mathrm{hr}$ prior to the time the behavior is elicited. For instance, the estradiol secreted prior to $-18 \mathrm{hr}$ is clearly not sufficient to induce sexual responsiveness at $+9 \mathrm{hr}$ (Experiment 1 ) yet it still may be necessary for this behavior to occur. In this regard, it is interesting to note that the positive feedback effects of estradiol on $\mathrm{LH}$ release can be eliminated by OVX at $-15 \mathrm{hr}$, but not at $-11 \mathrm{hr}$ or later times, in 4D females [22]. It was additionally demonstrated that exogenous estradiol treatment immediately following OVX at $-15 \mathrm{hr}$ reinstated the LH surge, but that estradiol given at $-15 \mathrm{hr}$ was ineffective following $-30 \mathrm{hr}$ OVX. It was concluded that the high levels of estradiol secreted after $-15 \mathrm{hr}$ cause an LH surge only if the lower estradiol levels available earlier in the cycle are permitted to act. Whether this may also be true of estradiol's regulation of lordosis remains to be determined.

\section{REFERENCES}

1. Anderson, J. N., E. J. Peck, Jr. and J. H. Clark. Estrogeninduced uterine responses and growth: Relationship to receptor estrogen binding by uterine nuclei. Endocrinology 96: $160-167,1975$.

2. Barfield, M. A. and R. D. Lisk. Advancement of behavioral estrus by subcutaneous injection of progesterone in the four-day cyclic rat. Endocrinology 87: 1096-1098, 1970.

3. Barfield, M. A. and R. D. Lisk. Relative contributions of ovarian and adrenal progesterone to the timing of heat in the 4-day cyclic rat. Endocrinology 94: 571-575, 1974.

4. Beach, F. A. and R. K. Orndoff. Variation in the responsiveness of female rats to ovarian hormones as a function of preceding hormonal deprivation. Hormones Behav. 5: $201-205,1974$

5. Blaustein, J. D. and G. N. Wade. Sequential inhibition of sexual behavior by progesterone in female rats: Comparison with a synthetic antiestrogen. J. comp. physiol. Psychol. (in press, 1977).

6. Brom, G. M. and N. B. Schwartz. Acute changes in the estrous cycle following ovariectomy in the golden hamster. Neuroendocrinology 3: $366-377,1968$.

7. Brown-Grant, K., D. Exley and F. Naftolin. Peripheral plasma oestradiol and luteinizing hormone concentrations during the oestrous cycle of the rat. J. Endocr. 48: 295-296, 1970.

8. Brown-Grant, K. and F. Naftolin. Facilitation of luteinizing hormone secretion in the female rat by progesterone. $J$. Endocr. 53: 37-46, 1972.
9. Butcher, R. L., W. E. Collins and N. W. Fugo. Plasma concentration of LH, FSH, prolactin, progesterone and estradiol-17b throughout the 4-day estrous cycle of the rat. Endocrinology 94: 1704-1708, 1974.

10. Ciaccio, L. A. and R. D. Lisk. Hormonal control of cyclic estrus in the female hamster. Am. J. Physiol. 221: 936-942, 1971.

11. Cidlowski, J. A. and T. G. Muldoon. Estrogenic regulation of cytoplasmic receptor populations in estrogen-responsive tissues of the rat. Endocrinology 95: 1621-1629, 1974.

12. Damassa, D. and J. M. Davidson. Effects of ovariectomy and constant light on responsiveness to estrogen in the rat. Hormones Behav. 4: 269-279, 1973.

13. Eaton, G. G., R. W. Goy and J. A. Resko. Brain uptake and metabolism of estradiol benzoate and estrous behavior in ovariectomized guinea pigs. Hormones Behav. 6: 81-97, 1975.

14. Feder, H. H., K. Brown-Grant and C. S. Corker. Pre-ovulatory progesterone, the adrenal cortex and the 'critical period' for luteinizing hormone release in rats. $J$. Endocr. 50: 29-39, 1971.

15. Feder, H. H. and L. P. Morin. Suppression of lordosis in guinea pigs by ethamoxy-triphetol (MER-25) given at long intervals $(34-46 \mathrm{hr})$ after estradiol benzoate treatment. Hormones Behav. 5: 63-71, 1974

16. Feder, H. H. and R. Silver. Activation of lordosis in ovariectomized guinea pigs by free and esterified forms of estrone, estradiol-17b and estriol. Physiol. Behav. 13: 251-255, 1974. 
17. Gorski, R. A. The neuroendocrine regulation of sexual behavior. In: Advances in Psychobiology, Vol. 2, edited by G. Newton and A. M. Riesen. New York: Wiley, 1974, pp. 1-58.

18. Green, R., W. G. Luttge and R. E. Whalen. Induction of receptivity in ovariectomized female rats by a single intravenous injection of estradiol-17b. Physiol. Behav. 5: 137-141, 1970.

19. Hardy, D. F. and J. F. DeBold. The relationship between levels of exogenous hormones and the display of lordosis by the female rat. Hormones Behav. 2: 287-297, 1971.

20. Hardy, D. F. and J. F. DeBold. Effects of repeated testing on sexual behavior of the female rat. J. comp. physiol. Psychol. 85: 195-202, 1973.

21. Joslyn, W. D., H. H. Feder and R. W. Goy. Estrogen conditioning and progesterone facilitation of lordosis in guinea pigs. Physiol. Behav. 7: 477-482, 1971.

22. Kalra, S. P. Observations on facilitation of the preovulatory rise of LH by estrogen. Endocrinology 96:23-28, 1975.

23. Kalra, S. P. and P. S. Kalra. Effects of circulating estradiol during rat estrous cycle on $\mathrm{LH}$ release following electrochemical stimulation of preoptic brain or administration of synthetic LRF. Endocrinology 94: 845-851, 1974.

24. Kalra, S. P. and P. S. Kalra. Temporal interrelationships among circulating levels of estradiol, progesterone and LH during the rat estrous cycle: Effects of exogenous progesterone. Endocrinology 95: 1711-1718, 1974.

25. Landau, I. T. The effect of subcutaneous vs. intraperitoneal administration of an anti-estrogen, CI-628, on estradiol- and estradiol benzoate-stimulated lordosis in the ovariectomized rat. Pharmac. Biochem. Behav. 5: 473-476, 1976.

26. Lisk, R. D. Hormonal regulation of sexual behavior in polyestrous mammals common to the laboratory. In: Handbook of Physiology - Endocrinology II, Part 1, edited by R. O. Greep. Bethesda: American Physiological Society, 1973, pp. 223-260.

27. Mann, D. R. and C. A. Barraclough. Role of estrogen and progesterone in facilitating LH release in 4-day cyclic rats. Endocrinology 93: 694-699, 1973

28. Mann, D. R., C. D. Korowitz and C. A. Barraclough. Adrenal gland involvement in synchronizing the preovulatory release of LH in rats. Proc. Soc. exp. Biol. Med. 150: 115-120, 1975.

29. McEwen, B. S., D. W. Pfaff, C. Chaptal and V. N. Luine. Brain cell nuclear retention of $\left[{ }^{3} \mathrm{H}\right]$ estradiol doses able to promote lordosis: Temporal and regional aspects. Brain Res. 86: $155-161,1975$

30. Naftolin, F., K. Brown-Grant and C. S. Corker. Plasma and pituitary luteinizing hormone and peripheral plasma oestradiol concentrations in the normal oestrous cycle of the rat and after experimental manipulation of the cycle.J. Endocr. 53: 17-30, 1972.

31. Nequin, L. G., J. A. Alvarez and C. S. Campbell. Alterations in steroid and gonadotropin release resulting from surgical stress during the morning of proestrus in 5-day cyclic rats. Endocrinology 97: 718-724, 1975 .
32. Nequin, L. G., J. A. Alvarez and N. B. Schwartz. Steroid control of gonadotropin release. J. ster. Biochem. 6: 1007-1012, 1975 .

33. Nequin, L. G. and N. B. Schwartz. Adrenal participation in the timing of mating and LH release in the cyclic rat. Endocrinology 88: $325-331,1971$.

34. Powers, J. B. Hormonal control of sexual receptivity during the estrous cycle of the rat. Physiol. Behav. 5: 831-835, 1970.

35. Powers, J. B. Anti-estrogenic suppression of the lordosis response in female rats. Hormones Behav. 6: 379-392, 1975.

36. Powers, J. B. and J. Moreines. Progesterone: Examination of its postulated inhibitory actions on lordosis during the rat estrous cycle. Physiol. Behav. 17: 493-498, 1976.

37. Quadagno, D. M. and G. K. W. Ho. The reversible inhibition of steroid-induced sexual behavior by intracranial cycloheximide. Hormones Behav. 6: 19-26, 1975.

38. Quadagno, D. M., J. McCullough and R. Langan. The effect of varying amounts of exogenous estradiol benzoate on estrous behavior in the rat. Hormones Behav. 3: 175-179, 1972.

39. Rabii, J. and W. F. Ganong. Responses of plasma 'estradiol' and plasma LH to ovariectomy, ovariectomy plus adrenalectomy, and estrogen injection at various ages. Neuroendocrinology 20: 270-281, 1976.

40. Rodriguez-Sierra, J. F., W. R. Crowley and B. R. Komisaruk. Vaginal stimulation in rats induces prolonged lordosis responsiveness and sexual receptivity. J. comp. physiol. Psychol. 89: $79-85,1975$.

41. Roy, E. J. and G. N. Wade. Binding of ${ }^{3} \mathrm{H}$-estradiol by brain cell nuclei and female rat sexual behavior: Inhibition by antiestrogens. Brain Res. 126: 73 -87, 1977.

42. Smith, M. S., M. E. Freeman and J. D. Neill. The control of progesterone secretion during the estrous cycle and early pseudopregnancy in the rat: Prolactin, gonadotropin and steroid levels associated with rescue of the corpus luteum of pseudopregnancy. Endocrinology 96: 219-226, 1975.

43. Tapper, C. M. and K. Brown-Grant. The secretion and metabolic clearance rates of oestradiol in the rat. J. Endocr. 64: $215-227,1975$.

44. Tapper, C. M., F. Greig and K. Brown-Grant. Effects of steroid hormones on gonadotrophin secretion in female rats after ovariectomy during the oestrous cycle. J. Endocr. 62: $511-525,1974$.

45. Terkel, A. S., J. Shryne and R. A. Gorski. Inhibition of estrogen facilitation of sexual behavior by the intracerebral infusion of actinomycin-D. Hormones Behav. 4: 377-386, 1973.

46. Weisz, J. and P. Gunsalus. Estrogen levels in immature female rats: True or spurious - ovarian or adrenal? Endocrinology 93: $1057-1065,1973$.

47. Zucker, I. Progesterone in the experimental control of the behavioural sex cycle in the female rat. J. Endocr. 38: $269-277,1967$. 